This item was submitted to Loughborough's Research Repository by the author.

Items in Figshare are protected by copyright, with all rights reserved, unless otherwise indicated.

\title{
Underlying inflammation has no impact on the oxidative stress response to acute mental stress
}

PLEASE CITE THE PUBLISHED VERSION

https://doi.org/10.1016/j.bbi.2014.03.009

\section{PUBLISHER}

(C) Elsevier

\section{VERSION}

AM (Accepted Manuscript)

\section{PUBLISHER STATEMENT}

This work is made available according to the conditions of the Creative Commons Attribution-NonCommercialNoDerivatives 4.0 International (CC BY-NC-ND 4.0) licence. Full details of this licence are available at: https://creativecommons.org/licenses/by-nc-nd/4.0/

\section{LICENCE}

CC BY-NC-ND 4.0

\section{REPOSITORY RECORD}

Wadley, Alexander J., Jet J.C.S. Veldhuijzen van Zanten, Nicola J. Paine, Mark T. Drayson, and Sarah Aldred. 2019. "Underlying Inflammation Has No Impact on the Oxidative Stress Response to Acute Mental Stress". figshare. https://hdl.handle.net/2134/27229. 


\section{Accepted Manuscript}

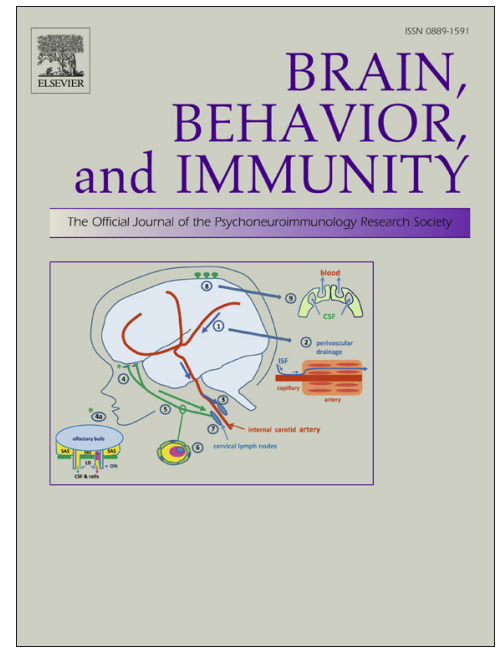

Underlying inflammation has no impact on the oxidative stress response to acute mental stress

Alex J. Wadley, Jet J.C.S. Veldhuijzen van Zanten, Nicola J. Paine, Mark T. Drayson, Sarah Aldred

PII:

DOI:

Reference:

To appear in:

Received Date:

Revised Date:

Accepted Date:
S0889-1591(14)00075-0

http://dx.doi.org/10.1016/j.bbi.2014.03.009

YBRBI 2336

Brain, Behavior, and Immunity

22 November 2013

6 March 2014

13 March 2014

Please cite this article as: Wadley, A.J., Veldhuijzen van Zanten, J.J.C., Paine, N.J., Drayson, M.T., Aldred, S., Underlying inflammation has no impact on the oxidative stress response to acute mental stress, Brain, Behavior, and Immunity (2014), doi: http://dx.doi.org/10.1016/j.bbi.2014.03.009

This is a PDF file of an unedited manuscript that has been accepted for publication. As a service to our customers we are providing this early version of the manuscript. The manuscript will undergo copyediting, typesetting, and review of the resulting proof before it is published in its final form. Please note that during the production process errors may be discovered which could affect the content, and all legal disclaimers that apply to the journal pertain. 


\section{Underlying inflammation has no impact on the oxidative stress}

\section{response to acute mental stress}

Alex, J. Wadley 1, 2** Jet, J.C.S. Veldhuijzen van Zanten ${ }_{1}$ Nicola, J. Paine 1, 3** Mark, T. Drayson $_{1,4}$ \& Sarah Aldred $_{1}$

1 School of Sport, Exercise and Rehabilitation Sciences, University of Birmingham, Edgbaston, Birmingham, B15 2TT, UK*

2 School of Sport, Exercise \& Health Sciences, Loughborough University, Leicestershire, LE11 3TU

3 Department of Psychiatry and Behavioural Sciences, Duke University Medical Centre, Durham, North Carolina, 27710, USA

${ }_{4}$ MRC Centre for Immune Regulation, School of Medical and Dental Sciences, University of Birmingham, Edgbaston, Birmingham, B15 2TT, UK

* All work was undertaken at the University of Birmingham, UK

** Present address

Keywords: Oxidative stress, psychological stress, myocardial infarction, cytokine, cardiovascular disease

Word Count: 5074 


\section{Address for correspondence:}

Dr Sarah Aldred

School of Sport, Exercise and Rehabilitation Sciences

College of Life \& Environmental Sciences

University of Birmingham

B15 2TT

United Kingdom

Email: s.aldred.1@bham.ac.uk

Phone: 01214147284

Fax: 01214144121 


\section{Abstract}

\section{Introduction}

Mental stress is considered to be a trigger for acute myocardial infarction (MI), with inflammation thought to provide a mechanism. Inflammation is reciprocally linked to oxidative stress, which has also been implicated in MI. The purpose of this study was to assess the effects of experimentally-induced inflammation on the oxidative stress response to mental stress in healthy participants.

\section{Methods}

Healthy males undertook one of two inflammatory stimuli: typhoid vaccination (Vaccination paradigm, $\mathrm{N}=17$ ) or eccentric exercise (Eccentric exercise paradigm, $\mathrm{N}=17$ ). All participants completed a mental arithmetic stress task twice (within-subject design): six hours after the inflammatory stimulus, and during a control non-inflammation condition. Blood samples were taken before, immediately and thirty minutes after the stress task. Plasma was assessed for interleukin-6 (IL-6), protein carbonyls (PC), lipid hydroperoxides (LOOH), total antioxidant capacity (TAC) and nitric oxide metabolites (NOx).

Results

Vaccination paradigm: IL-6, PC and NOx were significantly higher in the vaccination condition, relative to the control condition $(\mathrm{p}<.05)$. PC, TAC, LOOH and NOx were unchanged in response to mental stress in both the vaccination and control conditions. Eccentric Exercise paradigm: IL-6 and TAC were significantly higher in the eccentric exercise condition $(\mathrm{p}<.05)$, relative to the control condition. PC, TAC and NOx were unchanged in response to mental stress in both the eccentric exercise and control conditions.

\section{Conclusions}

Two different inflammatory paradigms were successful in increasing selective plasma markers of inflammation and oxidative stress prior to a mental stress task. However, 
experimentally induced transient inflammation had no impact on mental stress-induced changes in plasma $\mathrm{LOOH}, \mathrm{PC}$, TAC or NOx in young healthy participants. 


\section{Introduction}

Mental stress has been proposed as a potential trigger for myocardial infarction (MI) (Bergovec et al., 1992; Strike and Steptoe, 2005). The physiologic mechanisms linking mental stress to MI have not been fully clarified, however inflammation has been implicated (Paine and Veldhuijzen van Zanten, 2012; Wilbert-Lampen et al., 2010). Laboratory models have been used to investigate the role of inflammation in populations with elevated risk for cardiovascular disease and findings have shown that mental stress-induced ischemia is associated with future MI (Babyak et al., 2011; Krantz et al., 1999). Interestingly, mental stress-induced ischemia is more prevalent in those with higher baseline levels of inflammation (Shah et al., 2006). Inflammation is known to be intrinsically linked to oxidative stress, a state whereby the production of reactive oxygen species (ROS) overwhelms antioxidants (Wadley et al., 2012). Both oxidative stress and inflammation are independently associated with the development of cardiovascular disease (CVD) and MI (Cai and Harrison, 2000; Dhalla et al., 2000; Ross, 1999). Given the adverse effect of oxidative stress on MI risk, the relationship between mental stress and oxidative stress warrants further investigation.

The few studies that have investigated the links between oxidative stress and acute mental stress have primarily been in either animals (Bagchi et al., 1999; Madrigal et al., 2001) or observational studies in humans (Lesgards et al., 2002; Sivonova et al., 2004). For example, medical students undergoing a stressful examination period demonstrated increased DNA and lipid oxidation, as well as a deceased antioxidant capacity when compared to a non-stressful period of their life (Sivonova et al., 2004). Conversely, individuals delivering public speeches showed increased urinary concentrations of bilirubin oxidative metabolite, an abundant antioxidant compound, compared to a control group who did not perform a public speaking task (Yamaguchia et al., 2002). Similar disparity exists with acute mental stress and 
ROS production, with studies indicating increased (Bagchi et al., 1999) and suppressed (Atanackovic et al., 2002) production. Collectively, these studies warrant careful interpretation due the different study designs, categorisations of stress, measures of oxidative stress and the time points assessed. To our knowledge only one previous investigation has assessed the acute oxidative stress response to a controlled laboratory mental stress task (Huang et al., 2010). In this study, total antioxidant capacity (TAC), a marker of oxidative stress, was not perturbed in response to mental stress, however there are potential mechanisms which could explain an increase in oxidative stress in response to mental stress. For example, the well documented ROS burst from inflammatory neutrophils (Babior et al., 1973) could follow from a mental stress-induced inflammatory response (Brydon et al., 2005; Veldhuijzen van Zanten et al., 2005). Furthermore, altered blood flow and shear stress patterns (i.e. oscillatory shear) in response to mental stress (Veldhuijzen van Zanten et al., 2009) could generate ROS via vascular oxidases (Harrison et al., 2003), thus enhancing oxidative stress. Finally, a direct mechanism between oxidative stress and mental stressinduced MI might be explained by the actions of the diverse reactive nitrogen species (RNS), nitric oxide (NO). NO can regulate blood vessel dilation and vascular health (Lewis et al., 1999), however its function may be inhibited by mental stress-induced sequestering of NO by ROS (Beckman, 1996). Despite these potential mechanisms, the sources of oxidative stress and the mechanisms leading to MI as a result of mental stress have yet to be explored in detail.

There is evidence to suggest that ROS can trigger inflammatory pathways in humans (Naik and Dixit, 2011), and inflammation is known to drive ROS production (Babior et al., 1973). Studies in clinical populations with high underlying inflammation have reported an exaggerated inflammatory response to acute mental stress (Kop et al., 2008; Veldhuijzen van Zanten et al., 2008). It should be noted that, due to the underlying factors associated with 
these clinical populations (e.g., other cardiovascular risk factors), it is impossible to explore the direct effect of inflammation. As a result, laboratory based models have been used to induce an inflammatory response in healthy subjects (Clapp et al., 2004; Hingorani et al., 2000) and recently to specifically investigate the role of inflammation on mental stressinduced responses (Paine et al., 2013a). These studies have demonstrated that an acute rise in inflammation can influence the vascular responses to mental stress. However, the impact of baseline inflammation on the oxidative stress response to mental stress has yet to be examined.

Eccentric exercise-induced muscle damage and vaccination (Salmonella typhi (typhoid) capsular polysaccharide vaccine) have previously been used as models to induce systemic inflammation. In these studies, a peak inflammatory cytokine response was observed 6 hours following both inflammatory stimuli (Antoniades et al., 2011; MacIntyre et al., 2001; Paine et al., 2013b; Paulsen et al., 2005). The use of a low dose typhoid vaccination to induce a mild systemic inflammatory response is typically safe and approved by the US food and drug agency (Hingorani et al., 2000; Strike et al., 2004; Wright et al., 2005). The administration of a mild pathogen can stimulate the adaptive immune system to respond by mobilising white blood cells and increasing the production of inflammatory cytokines (Paine et al., 2013b). Similarly, eccentric exercise is commonly used as a safe experimental manipulation to study acute increases in inflammation (Paine et al., 2013a). Elongation of the activated muscle under tension can create a localized inflammatory response within the muscle that can infiltrate the systemic circulation (Nosaka et al., 2002; Proske and Morgan, 2001). In both of these models, the most typically studied inflammatory marker is Interleukin (IL-6), an acute phase protein with an active role in the inflammatory response (Papanicolaou et al., 1998). Importantly, IL-6 is a commonly used inflammatory marker in response to mental stress in the literature (Steptoe et al., 2007). 
To our knowledge no previous studies have explored changes in multiple markers of oxidative stress to acute mental stress following experimental manipulations of baseline inflammation. The aim of the current investigation was to use two inflammatory paradigms (vaccination and eccentric exercise) to assess how plasma markers of oxidative stress were perturbed in response mental stress. It was hypothesized that mental stress would elicit increases in oxidative stress, and that higher baseline levels of inflammation would exaggerate this response. 


\section{Methods}

\subsection{Participants}

\subsubsection{Vaccination paradigm}

Seventeen healthy males (mean \pm SD: age $20 \pm 1$ yrs; body mass index $24.5 \pm 2.2$.

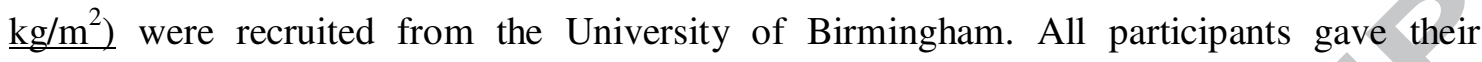
informed written consent and the vaccination paradigm of the study was approved by NHS Black Country NRES ethics committee. None of the participants had recently suffered from acute illness or infection. No participants reported a history of immune disorders, cardiovascular or other chronic inflammatory diseases and all participants were non-smokers. Participants were asked to refrain from vigorous exercise, alcohol and foods high in dietary nitrates 24 hours prior to testing. Participants were also asked to abstain from food and caffeine two hours before the morning and afternoon sessions. No participants had received a Salmonella typhi capsular polysaccharide vaccine in the preceding year.

\subsubsection{Eccentric Exercise paradigm}

Seventeen healthy males (mean \pm SD: age $21 \pm 1$ yrs; body mass index $23.6 \pm 2.4$. $\mathrm{kg} / \mathrm{m}^{2}$ ) were recruited from the University of Birmingham. The same exclusion and adherence criteria were used as indicated in the vaccination paradigm. In addition, all participants were unaccustomed to regular eccentric exercise training. As with the vaccination paradigm, participants gave their informed written consent and the eccentric exercise paradigm was approved by the appropriate ethics committee at the University of Birmingham. Participants were required to abstain from food and caffeine two hours before the morning and afternoon sessions.

\subsection{Vaccination Protocol}


Participants received an intra-muscular injection of $S$. typhi capsular polysaccharide vaccine $(0.025 \mathrm{mg}$ in $0.5 \mathrm{ml}$, Typhim Vi, Sanofi Pasteur, UK) into the deltoid muscle of the non-dominant arm. A trained nurse administered and then monitored the participant for half an hour following injection. Participants then completed questionnaires for demographic and medical purposes, as well as questionnaires addressing symptoms associated with the injection.

\subsection{Eccentric Exercise Protocol}

The eccentric exercise protocol was adapted from a previous study (Jackman et al., 2010). Using a Cybex leg extension machine (Cybex International Medway, MA), the 1 repetition maximum (1RM) of participant's non-dominant leg was determined. From a flexed position, participants were required to concentrically lift their leg into an extended position and hold for 2 seconds. 1RM was determined within 5 attempts to avoid fatigue. The 1RM was established when participants could no longer lift or hold the weight for longer than 2 seconds. The eccentric exercise task was then explained to participants before completing a practice set at 50\% $1 \mathrm{RM}$ to ensure an understanding of the task action. The task required participants to lower the weight $(120 \% 1 \mathrm{RM})$ with their dominant leg from an extended position (15 degrees flexion) to a flexed position (110 degrees flexion) over a 4 second period. Two experimenters lifted the weight into the extended position between repetitions. The protocol required participants to complete 12 sets of 5 repetitions with 5 seconds rest between each repetition and 1 minute rest in-between each set. Incomplete repetitions (i.e. where the weight was lowered in less than 4 seconds) were repeated. Participants then completed questionnaires for demographic and medical background purposes.

\subsection{Control Protocol}


In the eccentric exercise paradigm of the study, participants rested quietly for 25 minutes and then completed questionnaires administered for demographic and medical background information. No visit was required for subjects in the vaccination paradigm of the study.

\subsection{Mental Stress Task}

A 16-minute version of the paced auditory serial addition task (PASAT) was used to induce acute mental stress in all participants (Veldhuijzen van Zanten et al., 2005). A series of single digit numbers were dictated to participants via a $\mathrm{CD}$ player. The objective was to add each number to the previous number, vocalising the response to an accompanying demonstrator who was sat 1 metre away (Gronwall, 1977; Ring et al., 2002). Participants completed two 8 minute tasks, with a 1 minute interval between each task. The first task consisted of four consecutive 2 minute blocks, delivered at inter-stimulus rates of 2.8, 2.4, 2.0 and 1.6 seconds. The second task used inter-stimulus rates of 2.4, 2.0, 1.6 and 1.2 seconds, with the decrease in inter-stimulus rates increasing task difficulty. Additionally, several other experimental manipulations were implemented to enhance the mental stress response (Veldhuijzen van Zanten et al., 2004). The demonstrator checked participant responses against the correct answers, and a loud aversive noise was sounded within each block of 10 numbers upon the first incorrect or late response, or at the end of each block if no incorrect response was given. Participants were videotaped and instructed to focus their attention on a screen showing their face throughout the task. This manipulation was under the false instruction that they were being analysed by independent body language experts. Finally, a leader board was placed within subject eye line to promote competitiveness, and a promise of $£ 10$ for the highest study score in their first session and most improved score in session two. These experimental manipulations have been previously shown to increase provocativeness 
of the task by increasing demands such as time pressure, social evaluation, punishment and reward (MacIntyre et al., 2001; Veldhuijzen van Zanten et al., 2004; Woollard et al., 2002).

\subsection{Procedure}

Participants were subjected to one of the inflammatory paradigms (vaccination or eccentric exercise). All participants conducted the stress reactivity session twice which were scheduled at least seven days apart: once in an inflammation condition and once in a control condition (within-subject design). Both inflammation conditions involved a morning visit (starting: 08.00-10.00), during which the protocols described above was carried out, and an afternoon (starting 14.00-16.00) visit six hours later, during which the stress reactivity session was conducted. The six hour time window between the visits was based on pilot testing and previous research that indicates a peak inflammatory cytokine response to typhoid vaccination (Paine et al., 2013b) and eccentric exercise at this time point (MacIntyre et al., 2001). In the morning of the control condition, participants were either asked to attend the laboratory to complete questionnaires (eccentric exercise paradigm) or no visit was needed (vaccination paradigm). At the start of the first reactivity session, participants were asked to complete a diet questionnaire. A copy was then given to each participant and they were asked to repeat their diet before the second reactivity session.

\subsection{Stress Reactivity Session}

Following the assessments of height and weight (Seca Alpha, Hamburg, Germany), participants lay in a supine position for the remainder of the session. A small cuff was placed around the middle finger of the dominant hand for continuous recordings of heart rate (HR), systolic (SBP) and diastolic blood pressure (DBP) throughout the session (Finapres Medical Systems; Amsterdam, The Netherlands). Data were recorded via a Power 1401 (CED) connected to a computer with Spike 2 analysis software (version 6). A catheter (Becton, 
Dickson \& Company, Oxford, UK) was inserted into the antecubital vein of the dominant arm. The catheter was kept patent throughout the session with regular saline flushes. Participants rested for 20 minutes whilst watching a BBC nature documentary, with a blood sample taken (baseline). Following a practice, participants completed the mental stress task as detailed above. A blood sample was taken during the last minute of the second PASAT block (stress). Participants then completed a 30 minute recovery period, which involved participants resting in the supine position while watching a BBC nature documentary. A blood sample was taken at the end of this period (post +30$)$. Blood $(12 \mathrm{ml}$ per time point) was collected into vacutainers containing potassium ethylene diaminetetraacetic acid, stored on ice until centrifugation ( $1500 \mathrm{~g}$ for 10 minutes at $4^{\circ} \mathrm{C}$ ) and plasma aliquoted and stored at $80^{\circ} \mathrm{C}$ for future analyses.

\subsection{Blood Analyses}

Blood samples were assessed for blood cell composition, specifically total white blood cells and granulocytes. Haemoglobin (g/dL) and Hematocrit (\%) were assessed to calculate plasma volume changes as a result of mental stress (Coulter Analyser, BeckmanCoulter, High Wycombe, UK) (Kargotich et al., 1997).

\subsubsection{Total Antioxidant Capacity}

TAC was assessed using the Ferric Reducing Ability of Plasma (FRAP) assay (Benzie and Strain, 1996). Plasma samples (10 $\mu \mathrm{l}$ per well) and standards (ascorbic acid, 0-1000 $\mu \mathrm{M}$ ) were added in triplicate to a flat bottomed 96 well plate. FRAP reagent (300 mM sodium acetate $(\mathrm{pH}=3.6), 160 \mathrm{mM} 2,4,6$ - tripyridyltriazin and $20 \mathrm{mM}$ ferric chloride $\left.\left(\mathrm{FeCl}_{3}\right) ; 300 \mu \mathrm{l}\right)$ was added to each well and left to incubate for 8 minutes at room temperature, then absorbance's read at $650 \mathrm{~nm}$. TAC values were obtained using absorbance values of known 
ascorbic acid concentrations and expressed as $\mu \mathrm{M}$ of antioxidant power relative to ascorbic acid (McAnulty et al., 2005) and adjusted for plasma volume.

\subsubsection{Protein Carbonylation (PC)}

PC was assessed by ELISA (Buss et al., 1997; Carty et al., 2000) in order to quantify the degree of protein oxidation in plasma samples. Samples were diluted in coating buffer ( $50 \mathrm{mM}$ sodium carbonate, $\mathrm{pH}=9.2$ ) to a concentration of $0.05 \mathrm{mg} / \mathrm{ml}$. Samples and standards $(50 \mu 1)$ were added in triplicate to a 96 well NUNC maxisorb microtitre plate for 1 hour at room temperature. Bound protein was then incubated in the dark for 1 hour at room temperature with 2, 4-dinitrophenylhydrazine (DNPH) $(1 \mathrm{mM}$, in $2 \mathrm{M} \mathrm{HCl})$. All wells were then blocked $(200 \mu 1)$ with TBS Tween $(0.1 \%)$ overnight at $4{ }^{\circ} \mathrm{C}$. Wells were incubated with monoclonal mouse anti-DNP antibody $(50 \mu 1,1: 1000)$ for 2 hours at room temperature,

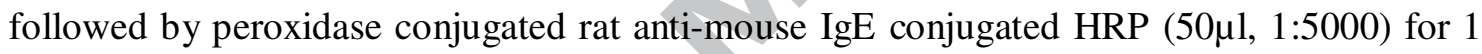
hour at room temperature. All steps were followed by three washes to the 96 well plate using TBS Tween $(0.05 \%)$. Substrate (0.5M Citrate phosphate buffer $(10 \mathrm{mls}, \mathrm{pH}=5)$, hydrogen peroxide $(8 \mu \mathrm{l})$ and Ortho-Phenylenediamine tablet $(2 \mathrm{mg}) ; 50 \mu \mathrm{l})$ was added to each well and the reaction stopped after 20-25 minutes with $2 \mathrm{M}$ sulphuric acid $(50 \mu \mathrm{l})$. Each well was measured for absorbance at 490nm (Multiscan MS, Labsystems) and quantified using absorbance values of PC standards made in our lab $(1.28-5.20 \mathrm{nM} / \mathrm{mg}$ of protein). Sample protein concentrations were determined using the bicinchoninic assay method (Smith et al., 1985).

\subsubsection{Lipid Hydroperoxides}

LOOH concentrations were assessed using a spectrophotometric assay (El-Saadani et al., 1989). Plasma samples and a blank standard (10 $\mu \mathrm{l})$ were added to a 96 well microtitre 
plate in triplicate. Reagent mix $(100 \mu \mathrm{l}, 0.2 \mathrm{M}$ Potassium phosphate $(\mathrm{pH}=6.2), 0.12 \mathrm{M}$ potassium iodide, $0.15 \mathrm{mM}$ sodium azide, Triton $\mathrm{X}(2 \mathrm{~g} / \mathrm{l})$, alkylbenzyldimethlammonium $(0.1 \mathrm{~g} / \mathrm{l}), 10 \mu \mathrm{M}$ ammonium molbdate and HPL grade water (to make total volume $100 \mathrm{ml}$ )) was added for 30 minutes at room temperature, away from light on a plate shaker. The plate was read at 340nm (Multiscan MS, Labsystems) and concentration of lipid peroxides ( $\mu$ mol/l) determined using the Beer-Lambert Law (extinction co-efficient $\varepsilon_{340}=24600 \mathrm{M}^{-1} \mathrm{~cm}^{-1}$ ) and adjusted for plasma volume.

\subsubsection{Nitrite and Nitrate (NOx metabolites)}

The Griess assay was used to quantify total nitric oxide metabolites (NOx) in plasma samples (Miranda et al., 2001; Moshage et al., 1995). Samples (100 $\mu$ l) were diluted with HPL grade water $(375 \mu \mathrm{l})$ and zinc sulphate $(25 \mu \mathrm{l}, 300 \mathrm{mg} / \mathrm{ml})$ to give a concentration of 15 $\mathrm{mg} / \mathrm{ml}$. Samples were vortexed and then centrifuged at $10,000 \mathrm{~g}$ for 20 minutes $\left(10{ }^{\circ} \mathrm{C}\right)$. Supernatants and standards $(100 \mu \mathrm{l})$ were added to a 96 well microtitre plate in triplicate, and $100 \mu \mathrm{l}$ vanadium (III) chloride $(8 \mathrm{mg} / \mathrm{ml})$ then added. Thorough mixing was ensured to fully reduce plasma nitrate to nitrite. Sulphanilamide $(50 \mu 1,2 \%)$ and $\mathrm{N}$-(1-naphthyl) ethylendiamine dihydrochloride $(50 \mu 1,0.1 \%)$ were then rapidly added to each well. Plates were incubated for 30 minutes at $37^{\circ} \mathrm{C}$. Absorbance values were read at $540 \mathrm{~nm}$, compared with values of known nitrite concentration $(0-100 \mu \mathrm{M})$ and adjusted for plasma volume.

\subsubsection{Interleukin-6}

Plasma concentrations of IL-6 were determined using a commercially available HighSensitivity ELISA kit according to manufacturer instructions ( $\underline{R \& D}$ Systems). Briefly, samples (200 $\mu 1$, diluted 1:1 with assay diluent) were incubated with a monoclonal antibody (200 $\mu \mathrm{l})$ derived against IL-6, and then substrate (50 $\mu \mathrm{l})$ and amplifier $(50 \mu \mathrm{l})$ solutions added 
to develop the colour change. Plates were washed intermittently to reduce non-specific binding. The reaction was stopped using $2 \mathrm{M}$ sulphuric acid $(50 \mu \mathrm{l})$ and absorbance's read at $490 \mathrm{~nm}$, with a wavelength correction at $650 \mathrm{~nm}$. Values were then obtained from a linear standard curve of known IL-6 concentrations $(0.156-10 \mathrm{pg} / \mathrm{ml})$.

\subsection{Data reduction and analysis}

HR, SBP and DBP were recorded continuously throughout the stress reactivity session. Data were analysed during minutes 14, 16, 18, and 20 of the baseline rest period, at 2-minute intervals during the stress task and at minutes $24,26,28$, and 30 of the recovery period. Subsequently, the values were averaged to derive an overall baseline, stress and post+30 value for HR, SBP and DBP. Statistical analyses were performed using SPSS (PASW Statistics, release 18.0, SPSS Inc., Chicago, IL, USA). Differences in baseline IL-6 values were assessed by independent samples t-tests. The effects of mental stress on oxidative stress and cardiovascular activity were assessed by 2 condition (vaccination or eccentric exercise, control) by 3 time (baseline, stress and post+30) repeated measures ANOVA, with Greenhouse-Geisser correction (Vasey and Thasey, 1987). Post hoc analysis of the interaction effects was performed by a test of simple effects by pairwise comparisons. Pearson correlations were conducted to examine associations between baseline inflammation and oxidative stress with changes in $\mathrm{LOOH}, \mathrm{PC}, \mathrm{TAC}$ or NOx from baseline to stress. These analyses were performed separately for control and inflammatory conditions. Statistical significance was accepted at the $p<.05$ level. 


\section{Results}

\subsection{Vaccination paradigm}

\subsubsection{Vaccination induced inflammation}

Figure 1 (left panel) shows the IL-6 concentrations at baseline in the control and vaccination conditions. IL-6 concentrations in the vaccination condition were higher than in the control condition $(p<.001)$, confirming that vaccination increased inflammation prior to the start of the stress task.

\subsubsection{Cardiovascular and immune responses}

Figure 2 (left panel) illustrates the white blood cell and cardiovascular responses to the mental stress task in control and vaccination conditions. Total white blood cell number was higher in the vaccination condition relative to the control condition (condition effect; $p<.001)$. Total white blood cells increased in response to mental stress in both conditions (time effects: $p<.001$ ). There was a significant condition * time interaction effect for total white blood cell number $(p=.024)$. Post hoc analyses revealed that total white blood cell number was elevated during stress in both conditions, but remained elevated post +30 , relative to baseline in the control condition only. HR increased over the course of the mental stress task and returned to baseline values in both conditions (time effects; $p<.001$ ). SBP and DBP increased over the course of the stress task and remained elevated above baseline values post+30 (time effects; $p$ 's <.05). No differences were observed in HR, SBP and DBP between conditions.

\subsubsection{Oxidative stress responses}

Figure 3 (left panel) illustrates the changes in markers of oxidative stress and nitric oxide metabolites in response to the mental stress task in control and vaccination conditions. PC and NOx values were higher in the vaccination condition than the control condition 
(condition effects; $p$ 's <.05). TAC, PC, LOOH and NOx were unaltered in response to mental stress in both conditions (time effects: $p$ 's $>.126$ ).

3.1.4. Associations between baseline oxidative stress and inflammation and oxidative stress responses to mental stress

No associations were observed when assessing the influence of baseline markers of oxidative stress and inflammation on the $\mathrm{LOOH}, \mathrm{PC}$, TAC or NOx response to mental stress in control or vaccination conditions.

\subsection{Eccentric exercise paradigm}

\subsubsection{Eccentric exercise induced inflammation}

Figure 1 (right panel) shows the IL-6 concentrations in the control and eccentric exercise conditions. IL-6 concentrations in the eccentric exercise condition were higher than in the control condition $(p=.01)$, confirming that eccentric exercise had increased inflammation prior to the start of the stress task.

\subsubsection{Cardiovascular and immune responses}

Figure 2 (right panel) illustrates the cardiovascular responses to the mental stress task in control and eccentric exercise conditions. Total white blood cell number increased during stress in both conditions $(p=.007)$, with no differences observed between conditions._HR increased immediately following the mental stress task and returned to baseline values in both conditions (time effect; $p<.001$ ). SBP and DBP increased immediately following the 
mental stress task and remained elevated above baseline values post +30 (time effects; $p$ 's $<.05)$. No differences were observed in HR, SBP and DBP between conditions.

\subsubsection{Oxidative stress responses}

Figure 3 (right panel) illustrates the changes in markers of oxidative stress and nitric oxide metabolites in response to the mental stress task in control and eccentric exercise conditions. TAC values were higher in the inflammation condition compared to the control condition (condition effect; $p=.011$ ). TAC, PC and NOx were unaltered in response to mental stress in both conditions. $\mathrm{LOOH}$ decreased in response to mental stress in the eccentric exercise condition only (time effect; $p<.05$ ).

\subsubsection{Associations between baseline oxidative stress and inflammation and oxidative stress} responses to mental stress

An association was found between baseline $\mathrm{LOOH}$ values and changes in $\mathrm{LOOH}$ between baseline and stress in the eccentric exercise condition only $(\mathrm{r}=-0.635, \mathrm{p}<.003)$. No other associations were observed when assessing the influence of baseline makers of oxidative stress and inflammation on the PC, TAC or NOx response to mental stress in control or eccentric exercise conditions. 


\section{Discussion}

The current study demonstrates that vaccination and eccentric exercise were successful models of inducing inflammation, as demonstrated by significantly higher IL-6 concentrations in the inflammation conditions compared to the control conditions (figure 1). Nevertheless, acute inflammation did not influence the oxidative stress response to mental stress in either paradigm of this study.

The oxidative stress response to mental stress has previously been unclear, either under conditions of high or basal inflammation. Previous studies have indicated an increase (Bagchi et al., 1999; Sivonova et al., 2004), decrease (Atanackovic et al., 2002; Yamaguchia et al., 2002) and no change (Huang et al., 2010) in indices of oxidative stress (i.e. plasma markers and ROS levels) in response to acute mental stress and during periods of lifestyle stress. Oxidation of macromolecules within the body is part of normal homeostatic processes that regulate cellular signalling, growth and adaptations within tissues. Many lifestyle factors, including health history, nutritional status (Møller et al., 1996) and even internal circadian rhythm (Kanabrocki et al., 2002) can influence the degree of oxidative modification to these macromolecules. As a result, previous observational studies monitoring the impact of mental stress on markers of oxidative stress/ROS at one 'snap shot' warrant careful interpretation. In addition, stressful situations (i.e. exam periods (Sivonova et al., 2004) and public speaking (Yamaguchia et al., 2002)) and study model (human (Atanackovic et al., 2002) and animal (Bagchi et al., 1999) models) have varied significantly between studies, making it hard to draw valid and robust conclusions. To our knowledge, this was the first study utilising well standardized laboratory models of both acute inflammation and mental stress to test the sole influence of baseline inflammation on the oxidative stress responses to mental stress in humans. Our findings show that mental stress did not increase PC, LOOH, TAC and NOx under conditions of basal or experimentally manipulated elevated inflammation (figure 3). 
Previous studies have suggested a role for baseline inflammation on physiological responses to mental stress (Roupe van der Voort et al., 2000; Shah et al., 2006; Veldhuijzen van Zanten et al., 2005). In the current study, we used two established experimental paradigms to induce inflammation in healthy participants to specifically assess the influence of inflammation on the oxidative stress responses to mental stress. The elevations in baseline IL-6 concentrations in both of the inflammatory conditions, relative to control were comparable to values observed in patients with coronary artery disease (Kop et al., 2008) and otherwise apparently healthy men who then suffered a MI (Ridker et al., 2000). Thus, the experimental manipulations induced increase in IL-6 values which were similar to those at risk for MI. Furthermore, the mental stress task used in the present study elicited a physiological response similar to previous studies (Paine et al., 2013a; Veldhuijzen van Zanten et al., 2005, 2004). Heart rate, blood pressure and total numbers of white blood cells increased in all conditions during the mental stress task (figure 2). As a result we cannot attribute the lack of change in markers of oxidative stress to the models of inflammation or mental stress utilized in the current study.

The potential sources of ROS in response to mental stress have not been previously clarified. Respiratory bursts from phagocytes (Babior et al., 1973) and increased oscillatory shear stress (Harrison et al., 2003) have been identified as two possible sources. Interestingly inflammation is known to increase the amount of circulating phagocytic cells and alter blood flow patterns (Nagel et al., 1994), therefore providing a clear rationale for increased oxidative stress in response to mental stress. The current data indicate that selective markers of oxidative stress were elevated at baseline in the inflammatory conditions only, although the responses were different between paradigms (figure 3). Vaccination induced protein oxidation and NO production, whilst in line with some previous work, eccentric exercise elicited an antioxidant response (Turner et al., 2011). Despite this, the same markers 
remained stable in response to mental stress. Interestingly, despite total white blood cell numbers being higher at baseline in both inflammatory conditions relative to control, this did not exacerbate any leukocyte subset responses to mental stress (data not shown). Given the role of respiratory bursts on RONS production, the similarity in white blood cell number may explain similar responses between control and inflammatory conditions.

It must be noted that a decrease in $\mathrm{LOOH}$ was observed in the inflammation condition in the eccentric exercise paradigm only (time effect: $\mathrm{p}<.05$ ) (figure $3 \mathrm{C}$, right panel). Further investigation revealed that the decrease in $\mathrm{LOOH}$ from baseline to post-stress was associated with higher baseline $\mathrm{LOOH}$ values $(\mathrm{r}=-0.635, \mathrm{p}<.003)$. Thus, this could suggest that elevated levels of oxidized lipids may have been removed in response to mental stress, rather than a reduction in lipid oxidation per se. However, this is speculation and warrants further investigation.

Given the complexity of redox events in vivo, it must be considered that specific, rather than global oxidative events may be occurring in response to mental stress. Oxidative adducts, i.e. protein and lipid modifications or altered antioxidant status are indirect markers of RONS-mediated actions. These markers are a good representation of non-cellular, global oxidative change. Further investigation is needed to monitor intracellular markers of oxidative stress, and cellular redox status in response to mental stress. Indeed, specific, rather than global oxidative changes have been observed in response to physiological stressors, such as exercise (Aldred and Rohalu, 2011). In addition, extensive time point analysis is required to account for potential 'delayed' responses to mental stress. Some previous studies have reported an increase in IL-6 within thirty minutes of stress (Burns et al., 2008; Edwards et al., 2006). However, other studies have reported increases in markers of inflammation up to 120 minutes following acute mental stress, with no differences observed at 30 minutes, relative to baseline (Brydon et al., 2004; Steptoe et al., 2001). Furthermore, physiological stimuli such 
vaccination (Clapp et al., 2004) and exercise (Michailidis et al., 2007) have been shown to elicit delayed increases in markers of oxidative stress.

It must be noted that only selective markers of oxidative stress were measured in the current study. Given the complexity of oxidative events in vivo, other plasma and indeed intracellular oxidative changes in response to mental stress cannot be dismissed. In addition, the measurement of leukocyte subset numbers and IL-6 as sole indicators of inflammation might be considered a limitation. However, IL-6 is an integral signalling cytokine molecule in the acute phase response, regulating the upregulation of numerous other inflammatory proteins (i.e. C-reactive protein, tumour-necrosis factor alpha and IL-1 and IL-10) and therefore a good representation of an inflammatory response (Febbraio et al., 2010). In addition, IL-6 is a known, robust responder to both vaccination (Paine et al., 2013b) and eccentric exercise (MacIntyre et al., 2001), peaking similarly at 6 hours. The current data provide evidence that experimentally manipulated baseline inflammation does not increase plasma oxidative stress responses to acute mental stress within thirty minutes in young and healthy males. 


\section{References}

Aldred, S., Rohalu, M., 2011. A moderate intensity exercise program did not increase the oxidative stress in older adults. Arch Gerontol Geriatr 53, 350-353.

Antoniades, C., Cunnington, C., Antonopoulos, A., Neville, M., Margaritis, M., Demosthenous, M., Bendall, J., Hale, A., Cerrato, R., Tousoulis, D., Bakogiannis, C. Marinou, K., Toutouza, M., Vlachopoulos, C., Leeson, P., Stefanadis, C., Karpe, F., Channon, K.M., 2011. Induction of vascular GTP-cyclohydrolase I and endogenous tetrahydrobiopterin synthesis protect against inflammation-induced endothelial dysfunction in human atherosclerosis. Circulation 124, 1860-70.

Atanackovic, D., Djordje Atanackovic, M.D., M. C. Brunner-Weinzierl, H.K., Serke, S., Deter, H.C., 2002. Acute psychological stress simultaneously alters hormone levels, recruitment of lymphocyte subsets and production of reactive oxygen species. Immunol. Investig. 21, 73-91.

Babior, B.M., Kipnes, R.S., Curnutte, J.T., 1973. Biological defense mechanisms. The production by leukocytes of superoxide, a potential bactericidal agent. J. Clin. Invest. $52,741-744$.

Babyak, M.A., Blumenthal, J.A., Hinderliter, A., Waugh, R.A., Coleman, R.E., Sherwood, A., 2011. Prognosis after change in left ventricular ejection fraction during mental stress testing in patients with stable coronary artery disease. Am. J. Cardiol. 105, 25-28.

Bagchi, D., Carryl, O.R., Tran, M.X.M., Bagchi, A., Garg, C.B., Williams, G.G., Milnes, J., Balmoori, D.J., Mitra, S.J., 1999. Acute and chronic stress-induced oxidative gastrointestinal mucosal injury in rats and protection by bismuth subsalicylate. Mol. Cell. Biochem. 31, 109-116.

Beckman, J.S., 1996. Oxidative damage and tyrosine nitration from peroxynitrite. Chem. Res. Toxicol. 9, 836-844.

Benzie, I.F., Strain, J.J., 1996. The ferric reducing ability of plasma (FRAP) as a measure of "antioxidant power": the FRAP assay. Anal. Biochem. 239, 70-76.

Bergovec, M., Sjerobabski, V., Farrar, G., Altmann, P., Blair, J.A., 1992. Acute myocardial infarction among civilians in Zagreb city area. Lancet 339, 303.

Brydon, L., Edwards, S., Jia, H., Mohamed-Ali, V., Zachary, I., Martin, J.F., Steptoe, A., 2005. Psychological stress activates interleukin-1beta gene expression in human mononuclear cells. Brain. Behav. Immun. 19, 540-6.

Brydon, L., Edwards, S., Mohamed-Ali, V., Steptoe, A., 2004. Socioeconomic status and stress-induced increases in interleukin-6. Brain. Behav. Immun. 18, 281-290.

Burns, V.E., Edwards, K.M., Ring, C., Drayson, M., Carroll, D., 2008. Complement cascade activation after an acute psychological stress task. Psychosom. Med. 70, 387-396. 
Buss, H., Chan, T.P., Sluis, K.B., Domigan, N.M., Winterbourn, C.C., 1997. Protein carbonyl measurement by a sensitive ELISA method. Free Radic. Biol. Med. 23, 361-366.

Cai, H., Harrison, D.G., 2000. Endothelial dysfunction in cardiovascular diseases: the role of oxidant stress. Circ Res 87, 840-844.

Carty, J.L., Bevan, R., Waller, H., Mistry, N., Cooke, M., Lunec, J., Griffiths, H.R., 2000. The effects of vitamin $\mathrm{C}$ supplementation on protein oxidation in healthy volunteers. Biochem Biophys Res Commun 273, 729-735.

Clapp, B.R., Hingorani, A.D., Kharbanda, R.K., Mohamed-Ali, V., Stephens, J.W., Vallance, P., MacAllister, R.J., 2004. Inflammation-induced endothelial dysfunction involves reduced nitric oxide bioavailability and increased oxidant stress. Cardiovasc Res 64, $172-178$.

Dhalla, N.S., Temsah, R.M., Netticadan, T., 2000. Role of oxidative stress in cardiovascular diseases. J. Hypertens. 18, 655-673.

Edwards, K.M., Burns, V.E., Ring, C., Carroll, D., 2006. Sex differences in the interleukin-6 response to acute psychological stress. Biol. Psychol. 71, 236-9.

El-Saadani, M., Esterbauer, H., El-Sayed, M., Goher, M., Nassar, A.Y., Jurgens, G., 1989. A spectrophotometric assay for lipid peroxides in serum lipoproteins using a commercially available reagent. J. Lipid Res. 30, 627-630.

Febbraio, M.A., Rose-John, S., Pedersen, B.K., 2010. Is interleukin-6 receptor blockade the Holy Grail for inflammatory diseases? Clin. Pharmacol. Ther. 87, 396-8.

Gronwall, D.M., 1977. Paced auditory serial-addition task: a measure of recovery from concussion. Percept. Mot. Ski. 44, 367-373.

Harrison, D., Griendling, K.K., Landmesser, U., Hornig, B., Drexler, H., 2003. Role of oxidative stress in atherosclerosis. Am J Cardiol 91, 7A-11A.

Hingorani, A.D., Cross, J., Kharbanda, R.K., Mullen, M.J., Bhagat, K., Taylor, M., Donald, a. E., Palacios, M., Griffin, G.E., Deanfield, J.E., MacAllister, R.J., Vallance, P., 2000. Acute Systemic Inflammation Impairs Endothelium-Dependent Dilatation in Humans. Circulation 102, 994-999.

Huang, C.J.J., Franco, R.L., Evans, R.K., Acevedo, E.O., 2010. Effects of mental challenge on neurovascular responses in healthy male subjects. Int J Psychophysiol 78, 225-230.

Jackman, S.R., Witard, O.C., Jeukendrup, A.E., Tipton, K.D., 2010. Branched-chain amino acid ingestion can ameliorate soreness from eccentric exercise. Med. Sci. Sports Exerc. $42,962-70$.

Kanabrocki, E.L., Murray, D., Hermida, R.C., Scott, G.S., Bremner, W.F., Ryan, M.D., Ayala, D.E., Third, J.H.L.C., Parvez, S., Nemchausky, B.A., Hooper, D.C., 2002. Circadian variation in oxidative stress markers in healthy and type II diabetic men. Chronobiol. Int. 19, 423-439. 
Kargotich, S., Goodman, C., Keast, D., Fry, R.., Garcia-Webb, P., Crawford, P.., Morton, A.., 1997. The influence of exercise-induced plasma volume changes on the interpretation of biochemical parameters used for monitoring exercise, training and sport. Sport. Med. 7 , $185-191$.

Kop, W.J., Weissman, N.J., Zhu, J., Bonsall, R.W., Doyle, M., Stretch, M.R., Glaes, S.B., Krantz, D.S., Gottdiener, J.S., Tracy, R.P., 2008. Effects of acute mental stress and exercise on inflammatory markers in patients with coronary artery disease and healthy controls. Am. J. Cardiol. 101, 767-73.

Krantz, D.S., Santiago, H.T., Kop, W.J., Merz, C., Bairey, N., Rozanski, A., Gottdiener, J.S., 1999. Prognostic value of mental stress testing in coronary artery disease. Am. J. Cardiol. 84, 1292-1297.

Lesgards, J.F., Durand, P., Lassarre, M., Stocker, P., Lesgards, G., Lanteaume, A., Prost, M., Lehucher-Michel, M.-P., 2002. Assessment of lifestyle effects on the overall antioxidant capacity of healthy subjects. Environ. Health Perspect. 110, 479-86.

Lewis, T.V., Dart, A.M., Chin-Dusting, J.P., Kingwell, B.A., 1999. Exercise training increases basal nitric oxide production from the forearm in hypercholesterolemic patients. Arter. Thromb Vasc Biol 19, 2782-2787.

MacIntyre, D.L., Sorichter, S., Mair, J., Berg, a, McKenzie, D.C., 2001. Markers of inflammation and myofibrillar proteins following eccentric exercise in humans. Eur. J. Appl. Physiol. 84, 180-6.

Madrigal, J.L., Olivenza, R., Moro, M.A., Lizasoain, I., Lorenzo, P., Rodrigo, J., Leza, J.C., 2001. Glutathione depletion, lipid peroxidation and mitochondrial dysfunction are induced by chronic stress in rat brain. Neuropsychopharmacology 24, 420-429.

McAnulty, S.R., McAnulty, L.S., Morrow, J.D., Khardouni, D., Shooter, L., Monk, J., Gross, S., Brown, V., 2005. Effect of daily fruit ingestion on angiotensin converting enzyme activity, blood pressure, and oxidative stress in chronic smokers. Free Radic Res 39, 1241-1248.

Michailidis, Y., Jamurtas, A.Z., Nikolaidis, M.G., Fatouros, I.G., Koutedakis, Y., Papassotiriou, I., Kouretas, D., 2007. Sampling time is crucial for measurement of aerobic exercise-induced oxidative stress. Med. Sci. Sports Exerc. 39, 1107-13.

Miranda, K.M., Espey, M.G., Wink, D.A., 2001. A rapid, simple spectrophotometric method for simultaneous detection of nitrate and nitrite. Nitric Oxide 5, 62-71.

Møller, P., Wallin, H., Knudsen, L.E., 1996. Oxidative stress associated with exercise, psychological stress and life-style factors. Chem. Biol. Interact. 102, 17-36.

Moshage, H., Kok, B., Huizenga, J.R., Jansen, P.L., 1995. Nitrite and nitrate determinations in plasma: a critical evaluation. Clin Chem 41, 892-896. 
Nagel, T., Resnick, N., Atkinson, W.J., Dewey Jr, C.F., Gimbrone Jr, M.A., 1994. Shear stress selectively upregulates intercellular adhesion molecule-1 expression in cultured human vascular endothelial cells. J Clin Invest. 94, 885-891.

Naik, E., Dixit, V.M., 2011. Mitochondrial reactive oxygen species drive proinflammatory cytokine production. J. Exp. Med. 208, 417-20.

Nosaka, K., Newton, M., Sacco, P., 2002. Muscle damage and soreness after endurance exercise of the elbow flexors. Med Sci Sport. Exerc 34, 920-927.

Paine, N.J., Ring, C., Aldred, S., Bosch, J. a, Wadley, A.J., Veldhuijzen van Zanten, J.J.C.S., 2013a. Eccentric-exercise induced inflammation attenuates the vascular responses to mental stress. Brain. Behav. Immun. 30, 133-42.

Paine, N.J., Ring, C., Bosch, J.A., Drayson, M.T., Veldhuijzen van Zanten, J.J.C.S., 2013b. The time course of the inflammatory response to the Salmonella typhi vaccination. Brain. Behav. Immun. 30, 73-9.

Paine, N.J., Veldhuijzen van Zanten, J.J.C.S., 2012. Inflammation and vascular responses to acute mental stress: implications for the triggering of myocardial infarction. Curr. Pharm. Des. 18, 1494-1501.

Papanicolaou, D.A., Wilder, R.L., Manolagas, S.C., Chrousos, G.P., 1998. The pathophysiologic roles of interleukin-6 in human disease. Ann. Intern. Med. 128, $127-$ 137.

Paulsen, G., Benestad, H.B., StroM-Gundersen, I., MoRkrid, L., LappegoRd, K.T., Raastad, T., 2005. Delayed Leukocytosis and Cytokine Response to High-Force Eccentric Exercise. Med. Sci. Sport. Exerc. 37, 1877-1883.

Proske, U., Morgan, D.L., 2001. Muscle damage from eccentric exercise: mechanism, mechanical signs, adaptation and clinical applications. J. Physiol. 537, 333-45.

Ridker, P.M., Rifai, N., Stampfer, M.J., Hennekens, C.H., 2000. Plasma Concentration of Interleukin-6 and the Risk of Future Myocardial Infarction Among Apparently Healthy Men 101, 1767-1772.

Ring, C., Drayson, M., Walkey, D.G., Dale, S., Carroll, D., 2002. Secretory immunoglobulin A reactions to prolonged mental arithmetic stress: inter-session and intra-session reliability. Biol Psychol 59, 1-13.

Ross, R., 1999. Atherosclerosis--an inflammatory disease. N Engl J Med 340, 115-126.

Roupe van der Voort, C., Heijnen, C.J., Wulffraat, N., Kuis, W., Kavelaars, a, 2000. Stress induces increases in IL-6 production by leucocytes of patients with the chronic inflammatory disease juvenile rheumatoid arthritis: a putative role for alpha(1)adrenergic receptors. J. Neuroimmunol. 110, 223-9. 
Shah, R., Burg, M.M., Vashist, A., Collins, D., Liu, J., Jadbabaie, F., Graeber, B., Earley, C., Lampert, R., Soufer, R., 2006. C-reactive Protein and Vulnerability to Mental-StressInduced Myocardial Ischemia. Mol. Med. 12, 269-274.

Sivonova, M., Zitnanova, I., Hlincikova, L., Skodacek, I., Trebaticka, J., Durackova, Z., 2004. Oxidative stress in university students during examinations. Stress 7, 183-188.

Smith, P.K., Krohn, R.I., Hermanson, G.T., Mallia, A.K., Gartner, F.H., Provenzano, M.D., Fujimoto, E.K., Goeke, N.M., Olson, B.J., Klenk, D.C., 1985. Measurement of protein using bicinchoninic acid. Anal. Biochem. 150, 76-85.

Steptoe, A., Hamer, M., Chida, Y., 2007. The effects of acute psychological stress on circulating inflammatory factors in humans: a review and meta-analysis. Brain Behav. Immun. 21, 901-912.

Steptoe, A., Willemsen, G., Owen, N., Flower, L., Mohamed-Ali, V., 2001. Acute mental stress elicits delayed increases in circulating inflammatory cytokine levels. Clin Sci 101, $185-192$.

Strike, P.C., Steptoe, A., 2005. Behavioral and emotional triggers of acute coronary syndromes: a systematic review and critique. Psychosom. Med. 67, 179-86.

Strike, P.C., Wardle, J., Steptoe, A., 2004. Mild acute inflammatory stimulation induces transient negative mood. J. Psychosom. Res. 57.

Turner, J.E., Bosch, J.A., Drayson, M.T., Aldred, S., 2011. Assessment of oxidative stress in lymphocytes with exercise. J. Appl. Physiol. 111, 206-11.

Vasey, M.., Thasey, J.., 1987. The continuing problem of false positives in repeated measures ANOVA in psychophysiology - A multivariate solution. Psychophysiology 24, 479486.

Veldhuijzen van Zanten, J.J., Ring, C., Carroll, D., McIntyre, D., Brown, M.D., 2009. Hemoconcentration during a prolonged stress task: associations with hemodynamic reactivity and microvascular permeability. Biol Psychol 82, 260-266.

Veldhuijzen van Zanten, J.J.C.S., Kitas, G.D., Carroll, D., Ring, C., 2008. Increase in systemic vascular resistance during acute mental stress in patients with rheumatoid arthritis with high-grade systemic inflammation. Biol Psychol 77, 106-110.

Veldhuijzen van Zanten, J.J.C.S., Ring, C., Burns, V.E., Edwards, K.M., Drayson, M.T., Carroll, D., 2004. Mental stress-induced hemoconcentration: sex differences and mechanisms. Psychophysiology 42, 98-107.

Veldhuijzen van Zanten, J.J.C.S., Ring, C., Carroll, D., Kitas, G.D., 2005. Increased C reactive protein in response to acute stress in patients with rheumatoid arthritis. Ann Rheum Dis 64, 1299-1304. 
Wadley, A.J., Veldhuijzen van Zanten, J.J.C.S., Aldred, S., 2012. The interactions of oxidative stress and inflammation with vascular dysfunction in ageing: the vascular health triad. Age (Omaha). 35, 705-718.

Wilbert-Lampen, U., Nickel, T., David, L., Güthlin, D., Matis, T., Christoph Völker, S.S., Helmut Küchenhoff, S.K., Steinbeck, G., 2010. Modified Serum Profiles of Inflammatory and Vasoconstrictive Factors in Patients With Emotional Stress-Induced Acute Coronary Syndrome During World Cup Soccer 2006. J. Am. Coll. Cardiol. 57, 637-642.

Woollard, K.J., Phillips, D.C., Griffiths, H.R., 2002. Direct modulatory effect of C-reactive protein on primary human monocyte adhesion to human endothelial cells. Clin Exp Immunol 130, 256-262.

Wright, C.., Strike, P.C., Brydon, L., Steptoe, A., 2005. Acute inflammation and negative mood: Mediation by cytokine activation. Brain Behav. Immun. 19, 345-350.

Yamaguchia, T., Shiojib, I., Sugimotoc, A., Yamaokad, M., 2002. Psychological stress increases bilirubin metabolites in human urine. Biochem. Biophys. Res. Commun. 293, 517-520.

\section{Author Contributions}

All authors contributed to the following aspects of this study: conception and design of experiments, collection analysis and interpretation of data, and drafting the article and revising it critically for important intellectual content.

\section{Acknowledgments}

None of the authors declare a conflict of interest. Funding: University of Birmingham, UK.

Figure 1: Figure 1 shows the IL-6 concentrations in the vaccination paradigm (left panel) and the eccentric exercise paradigm (right panel). \# indicates a significant difference between control (grey bars) and inflammatory conditions (black bars) $(p<.05)$. 
Figure 2: Figure 2 shows the changes in white blood cell number (A), heart rate (B), systolic blood pressure (C) and diastolic blood pressure (D) at baseline, during and 30 minutes following the mental stress task in both the control and inflammation condition in the vaccination paradigm (left panel) and the eccentric exercise paradigm (right panel). Data are means \pm standard error. * indicates significant differences relative to baseline in the control condition $(p<.05)$. ** indicates significant differences relative to baseline in the inflammation condition $(p<.05)$. \# indicates significant differences relative to stress in the control condition $(p<.05)$. \#\# indicates significant differences relative to stress in the inflammation condition $(p<.05) .++$ indicates a significant difference between control and inflammatory conditions $(p<.05)$. Control condition (-) Inflammatory conditions (- - -).

Figure 3: Figure 3 shows the changes in TAC (A), PC (B), LOOH (C) \& NOx (D) at baseline, stress and 30 minutes following the mental stress task in the vaccination paradigm (left panel) and the eccentric exercise paradigm (right panel). Data are means \pm standard error. ** indicates significant changes relative to baseline $(p<.05)$. \# indicates a significant difference between control and inflammatory conditions $(p<.05)$. ). Control condition $(-)$ Inflammatory conditions (- - ). 
Figure 1

Vaccination Paradigm

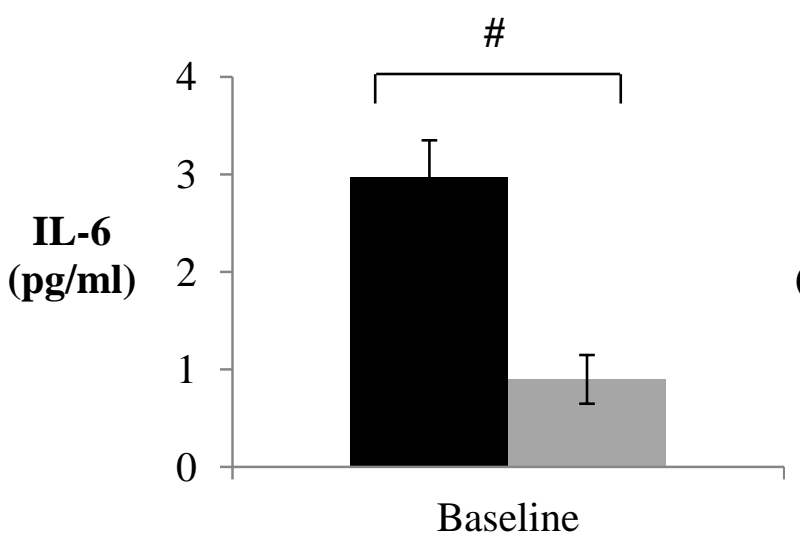

Eccentric Exercise Paradigm

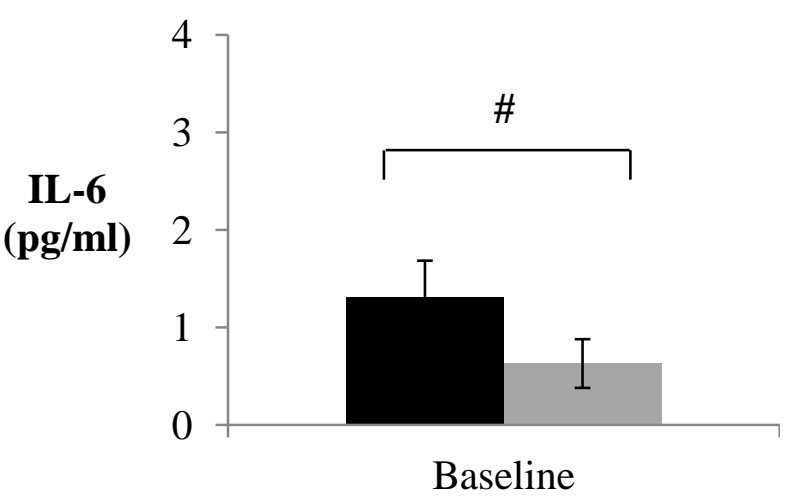


Figure 2
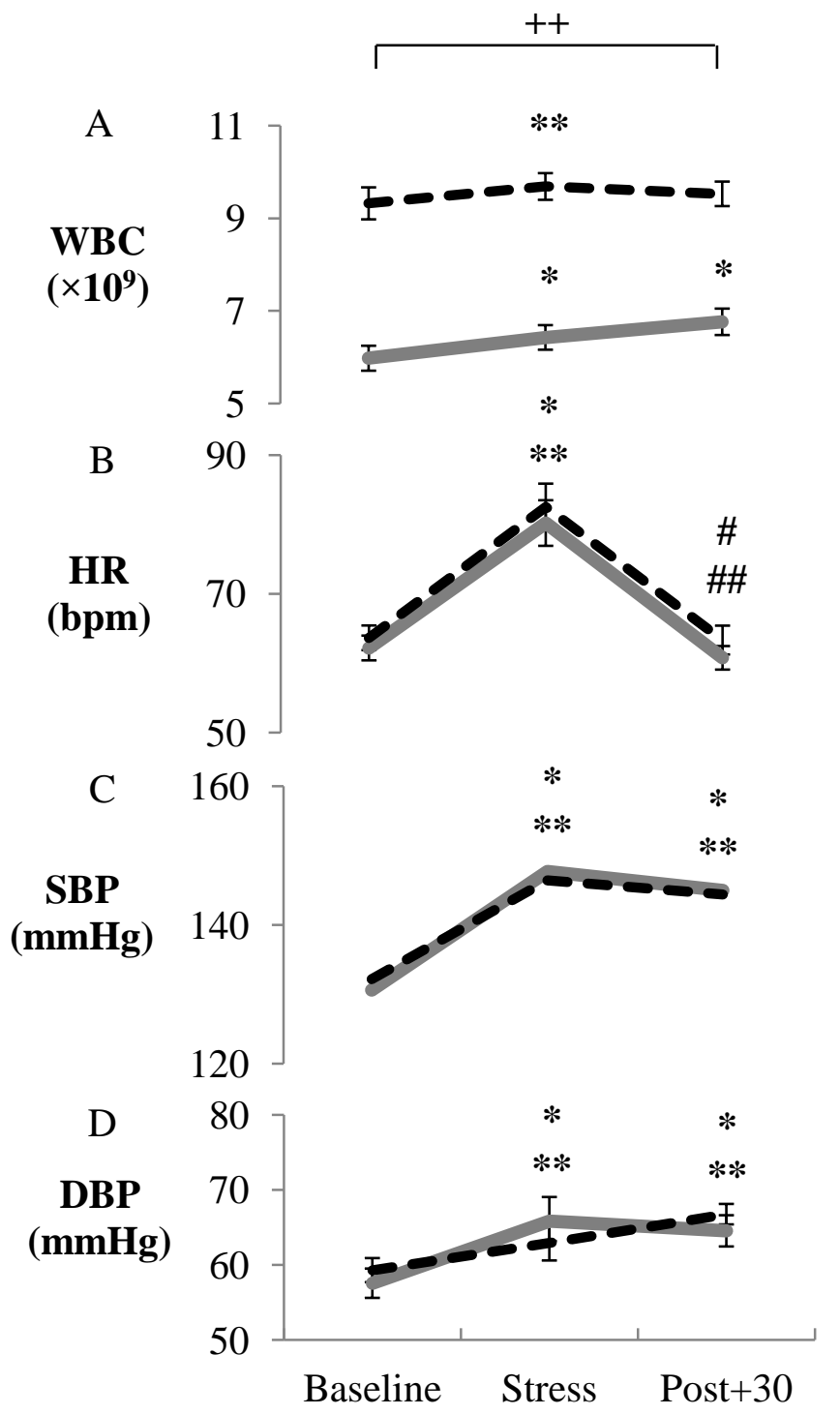
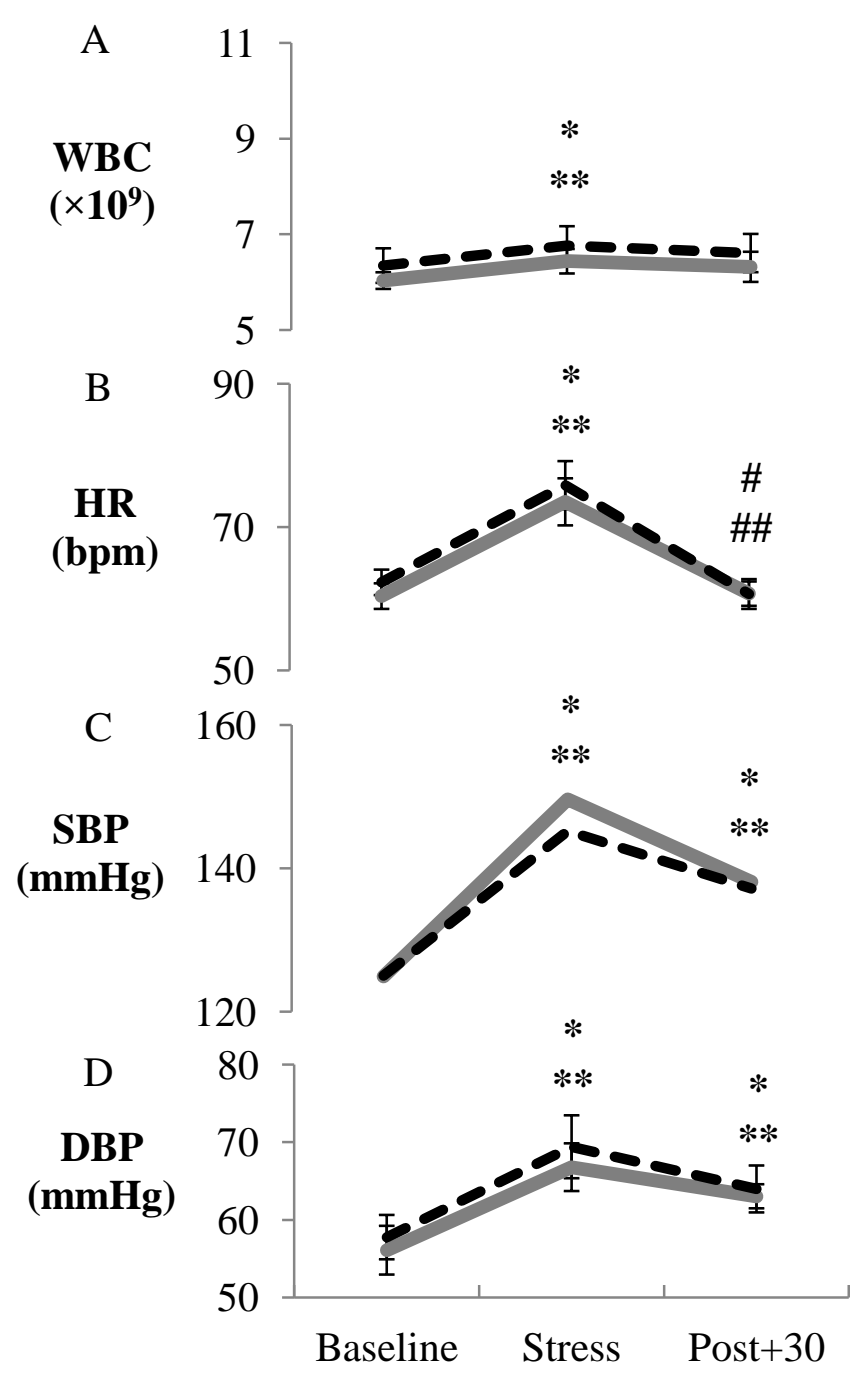
Figure 3

Vaccination Paradigm
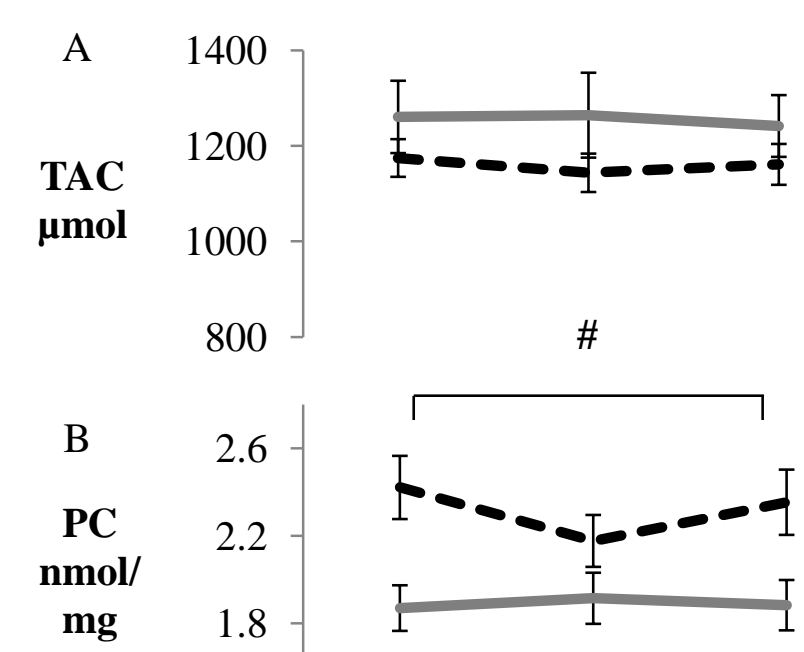

protein

$\left.\begin{array}{cr}\mathrm{C} & 20 \\ \mathbf{L O O H} & 15 \\ \text { peroxides } & 10 \\ \mathbf{\text { ml }} & 5 \\ \text { plasma } & 0\end{array}\right]$
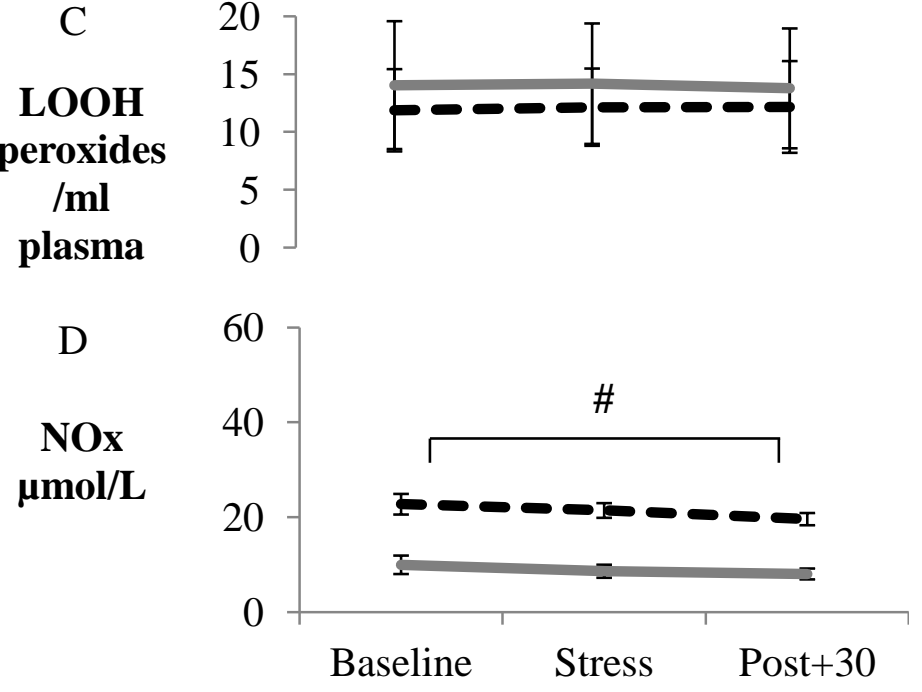

Eccentric Exercise Paradigm
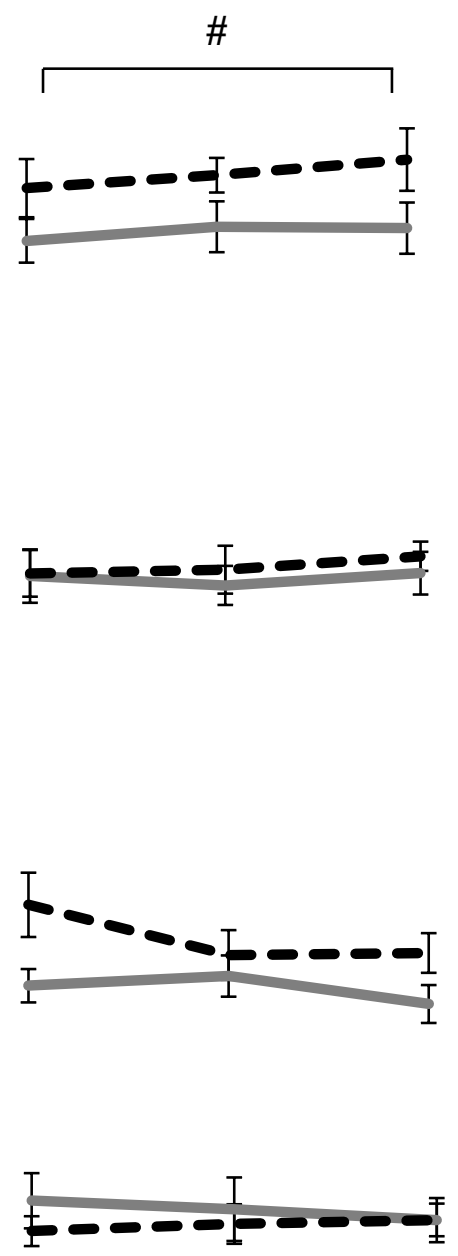

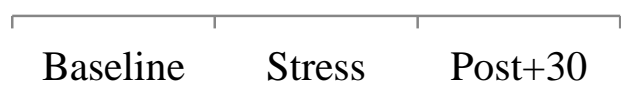

